\title{
Evidence for high rates of in-pair paternity in the socially monogamous snapping shrimp Alpheus angulosus
}

\author{
Lauren M. Mathews* \\ Department of Biology, Worcester Polytechnic Institute, 100 Institute Road, Worcester, Massachusetts 01609, USA
}

\begin{abstract}
Understanding the relationships between social and genetic interactions among individuals can lead to important insights into both the evolution of social behavior and the movement of alleles among generations. However, socially monogamous behavior is not always a good predictor of genetic parentage, so that inferences into genetic relationships among family group members require molecular genetic investigation. In the speciose snapping shrimp genera, social monogamy is the most common social system. However, research into mating and parentage relationships between socially monogamous partners has been limited by the reclusive nature of most snapping shrimp, which makes them difficult to observe under natural conditions, and so the degree to which social monogamy correlates with genetic monogamy remains unknown. Here, using data from 5 polymorphic microsatellite markers, evidence for high rates ( $\geq 94 \%$ of offspring genotyped) of in-pair paternity in field-captured heterosexual pairs of Alpheus angulosus, a common intertidal alpheid, is reported. Therefore, male social partners were apparently the sole or primary fathers of their female partners' clutches in all pairs. Some clutches showed evidence of 3+ paternal alleles at one of the genotyped loci, which may be a signal of multiple paternity; however, in these cases, the possibility of genotyping errors cannot be discounted. In summary, these data indicate that social monogamy correlates closely with genetic monogamy in this taxon, though additional work is required in order to draw strong inferences about the occurrence of multiple paternity of individual clutches.
\end{abstract}

KEY WORDS: Genetic parentage · Social monogamy · Extra-pair paternity · Snapping shrimp · Alpheus angulosus $\cdot$ Microsatellites

Resale or republication not permitted without written consent of the publisher

\section{INTRODUCTION}

The study of social and mating interactions among individuals has been greatly influenced in the last several decades by parental investment theory, formally articulated by Trivers (1972). This theory suggests that sexual conflict, originating from early differential investment in offspring by parents of different sexes, should often result in antagonistic behavior by males and females, even if they share a mutual interest in the successful rearing of offspring. The strength of sexual conflict, and therefore the extent to which it influences male and female behavior, is predicted to be a function of many ecological, physiological, and phylogenetic factors, but for a large majority of spe- cies, the general direction of the sexual conflict should be similar. Specifically, males should be under stronger selection than females to desert their partners in order to pursue additional matings, because for males, the costs of abandonment are generally lower and the benefits of additional matings are generally higher (Trivers 1972).

However, social monogamy has been documented in a broad range of taxa (reviewed in Mathews 2002a), and is thought to have evolved in response to a number of selective pressures, such as the net fitness benefits of shared direct or indirect parental care (Gardner et al. 2002), the high costs of mate-searching (Seibt \& Wickler 1979, Brotherton et al. 1997), and a net fitness benefit which may result from sharing a territory 
(Mathews 2002a). In such cases, both males and females should be under selection to engage in extrapair copulations (EPCs) whenever there is a net fitness benefit for doing so. For example, males that engage in EPCs stand to benefit by fertilizing all or part of an extra-pair female's brood. Likewise, a female that engages in EPCs may receive a number of fitness advantages, such as genetic benefits (Foerster et al. 2003, Bouwman et al. 2006, Cohas et al. 2006) or a reduction in the costs of harassment by extra-pair males (Lee \& Hays 2004). However, an individual of either gender that engages in EPCs may pay a substantial cost, such as cuckoldry due to relaxed mate-guarding of its own social partner (Kokko \& Morrell 2005) and the transmission of diseases (Poiani \& Wilks 2000). Therefore, an individual's decision to engage in EPC should be based on a complex set of physiological and ecological factors that may vary not only from population to population, but also among individuals within a population.

Snapping shrimp are invertebrate representatives of socially monogamous taxa; many members of the genera Alpheus, with 220 species, and Synalpheus, with 115 species (Chace 1988), are commonly found in heterosexual pairs. In many crustaceans, including alpheids, females are able to mate and fertilize eggs only within a brief period of time, often following the molt (Nelson 1991, Correa \& Thiel 2003, Mathews 2003). In addition, although females of some crustaceans possess sperm storage structures (Subramoniam 1993), there are no such structures in female caridean shrimp, and Bauer (2004) considered that female carideans are unlikely to carry sperm through a molt cycle. There is no evidence that females of Alpheus angulosus (the focus of the current investigation) are able to store sperm; females maintained in isolation through a molt do not produce embryos (L. M. Mathews pers. obs.).

In general, reports of socially monogamous behavior in snapping shrimp have been anecdotal, and only a few species have been formally investigated (e.g. Knowlton 1980, Mathews 2002a,b, 2003, Rahman et al. 2003). In all alpheids that have been examined empirically, the social structure consists of size-matched, heterosexual pairs cohabiting and codefending a territory against all conspecific and heterospecific alpheids, and, at least for Alpheus angulosus, males and females defend their territories against conspecifics of both genders (Mathews 2002a). Mathews (2002b) found that $\sim 87 \%$ of a population of $A$. angulosus occurred as heterosexual pairs. In laboratory experiments (Mathews 2002a,b), males of A. angulosus adjusted their behavior with respect to their expectation of future matings both with their social partners and with extra-pair females, indicating that, for males, pairing is a function of the relative values of the females potentially available as mates, and that changes in relative reproductive values of available females may result in periodic mate-switching by males. In addition, males may theoretically sneak copulations with neighboring females: the burrows occur as a dense, complex interconnecting network of tunnels (L. Mathews pers. obs.), and underground physical contact between territorial neighbors is likely to occur. On the other hand, because of territorial aggression against conspecifics of either gender by both male and female partners (Mathews 2002a), opportunities for EPCs may be limited, resulting in a close correlation between social and genetic monogamy.

To investigate mating patterns in Alpheus angulosus, parentage analyses were carried out on a sample of individuals collected from a population in Fort Pierce, Florida, USA, using variable microsatellite markers as described by Mathews (2006). Because females attach developing embryos to their pleopods (Bauer 2004), maternity was known for all clutches, and social partners were considered as putative fathers of the females' broods. The primary goal of this research was to investigate the relationship between pairing and mating interactions, i.e. Are social partners always the sires of a female's clutch of eggs, and, if not, at what frequency does extra-pair paternity occur? The data set was also investigated for signals of multiple paternity within single clutches of eggs, which has been reported for some crustacean species in which females store sperm (Walker et al. 2002, Gosselin et al. 2005) and in others for which no sperm storage structure is known (Toonen 2004, Bilodeau et al. 2005). In addition, Urbani et al. (1998) reported the presence of multiple ejaculates in the sperm storage structures of female snow crabs, but no evidence that more than one male was successful in fertilizing part of a female's clutch. For caridean shrimp, in which mating must occur quickly and females are unlikely to store sperm, opportunities for polyandry may be limited. However, Thiel \& Correa (2004) found that females of the caridean shrimp Rhynchocinetes typus mate rapidly with successive males, and therefore may have spermatophores from multiple males when they oviposit. In caridean shrimp, therefore, multiple paternity of single clutches may be possible, but this has not yet been investigated.

\section{MATERIALS AND METHODS}

Collection and genetic analysis. Shrimp were collected from a population in Fort Pierce, Florida, USA, in May 2004. Individuals of Alpheus angulosus occur in patches of habitat where the substrate consists of a mixture of larger (rocks and broken shell) and smaller 
(sand or mud) particles, and A. angulosus are apparently unable to burrow in sand or mud flats. Shrimp were sampled from one such patch by haphazardly selecting four $1 \mathrm{~m}^{2}$ quadrats within the $\sim 25 \mathrm{~m}^{2}$ patch. Within each quadrat, shrimp were collected by digging $\sim 20$ to $30 \mathrm{~cm}$ into the substrate and gathering shrimp by hand. Population densities of this species tend to be high ( 20 to 30 shrimp $\mathrm{m}^{-2}$; Mathews 2002b), with the top layer of substrate comprising a complex network of interconnected burrows. Shrimp were categorized as 'paired' when 2 shrimp were found within $5 \mathrm{~cm}$ of one another; in many cases, shrimp meeting this requirement were in actual physical contact. No same-sex pairs were found. Snapping shrimp in close proximity are likely to be social partners because individuals are highly aggressive to non-partners of either gender (Mathews 2002a).

In the field, females were examined for the presence of developing embryos. For females that were brooding embryos ( $86 \%$ of all paired and unpaired females), embryo development was estimated as the percent of egg volume taken up by yolk. Pilot investigations indicated that DNA extractions on eggs containing little yolk were more likely to yield high-quality genomic DNA than extractions on eggs containing much yolk. All shrimp found in each quadrat were placed as collected (paired or singly) in $50 \mathrm{ml}$ conical tubes with perforations for water circulation, and returned to the Tropical Research Laboratory of Mote Marine Laboratory (TRL) for processing. All males, and females brooding late-stage embryos with little yolk, were euthanized immediately by freezing. All other females brooding undeveloped embryos were stored individually in $50 \mathrm{ml}$ conical tubes in flow-through seawater tables at TRL, and were examined daily for embryo development. These females were euthanized as their embryos developed, over a total period of $10 \mathrm{~d}$ from the day of collection. All shrimp were shipped to Worcester Polytechnic Institute (WPI) in liquid nitrogen.
From each female, embryos were removed from the clutch, ensuring that the collection of genotyped embryos represented a sample of the entire clutch (i.e. each embryo was selected from a different location in the clutch). From most females, a total of 14 embryos was included in the genotyping analysis, except from females brooding fewer than 14 embryos; in these cases, all embryos were used. In Alpheus angulosus, most clutches comprise at least several hundred embryos, but occasionally females are found with far fewer, but still fertile, embryos (L. M. Mathews pers. obs.). Embryos were placed individually in $100 \mathrm{ml}$ of cell lysis solution (Gentra PureGene DNA extraction kit). From adults, muscle samples were taken from the abdomen and placed in $300 \mathrm{ml}$ of cell lysis solution. Genomic DNA was extracted from adult samples and embryos following the PureGene protocol and quantified by gel electrophoresis. Polymerase chain reactions (PCR) were carried out on 5 variable microsatellite loci (Table 1) using the primer combinations and reaction conditions described in Mathews (2006). PCR products were analyzed on an ABI 3730xl DNA Analyzer with GeneScan 600 LIZ size standard at the Biotechnology Resource Center at Cornell University, and results were scored by eye using GeneMapper v.3.0 (ABI).

The program CERVUS (Marshall et al. 1998) was used to calculate expected and observed heterozygosities, to test for departures from Hardy-Weinberg equilibrium, and to calculate the exclusion probabilities for each locus and for all loci, under the assumption of one parent known. The program GenePop v.3.3 (Raymond $\&$ Rousset 1995) was used to test for linkage disequilibrium, using the genotyping data set from all adult shrimp. The frequency of genotyping errors was assessed by repeated $(n=5)$ PCR amplification and genotyping of a randomly selected subset of 20 adults (15\% of the total adult collection) at each locus; the program GIMLET v.1.3.2 (Valière 2002) was used to construct consensus genotypes for these 20 adults and

Table 1. Alpheus angulosus. Basic information from genotyping data. $N_{\mathrm{A}}=$ number of alleles; $H_{\mathrm{o}}=$ observed heterozygosity; $H_{\mathrm{e}}=$ expected heterozygosity; $\mathrm{FA}=$ false alleles; $\mathrm{NA}=$ null alleles. $N_{\mathrm{A}}, H_{\mathrm{o}}, H_{\mathrm{e}}$, and exclusion probabilities were calculated from adult genotypes only; error rates were calculated from a random sampling of $n=20$ adults

\begin{tabular}{|c|c|c|c|c|c|c|c|c|}
\hline \multirow[t]{2}{*}{ Locus } & \multirow[t]{2}{*}{$N_{\mathrm{A}}$} & \multirow[t]{2}{*}{$H_{\mathrm{o}}$} & \multirow[t]{2}{*}{$H_{\mathrm{e}}$} & \multirow{2}{*}{$\begin{array}{l}\text { Exclusion } \\
\text { probability }^{\mathrm{a}}\end{array}$} & \multicolumn{2}{|c|}{ Error rates } & \multicolumn{2}{|c|}{$\longrightarrow$ No. of families with } \\
\hline & & & & & FA & NA & $\begin{array}{l}\geq 1 \text { father-offspring } \\
\text { mismatch }\end{array}$ & $\begin{array}{c}\geq 1 \text { mother-offspring } \\
\text { mismatch }\end{array}$ \\
\hline Aa13 & 9 & 0.698 & 0.668 & 0.428 & 0.000 & 0.014 & 1 & 1 \\
\hline Aa16 & 18 & 0.954 & 0.917 & 0.827 & 0.000 & 0.015 & 5 & 2 \\
\hline Aa22 & 29 & 0.813 & 0.824 & 0.669 & 0.000 & 0.029 & 3 & 5 \\
\hline Aa36 & 6 & $0.570^{\mathrm{b}}$ & 0.480 & 0.255 & 0.024 & 0.025 & 1 & 0 \\
\hline Aa39 & 20 & 0.908 & 0.869 & 0.738 & 0.000 & 0.040 & 5 & 0 \\
\hline
\end{tabular}


to estimate the rates of allelic dropout and false allele scoring. For all parentage analyses, maternity was considered to be known. Because the collection of shrimp comprises only a small subset (in both number and sampled area) of the total patch population, sampled females may have had contact with males that were not included in the collection.

Paternal genotype reconstruction and analysis. For all females brooding embryos $(\mathrm{n}=54)$, the minimum number of fathers was estimated and paternal genotypes were reconstructed using the program GERUD v.2.0 (Jones 2005). When the maternal genotype is known, GERUD yields either all possible single paternal genotypes (if the minimum number of fathers is one) or all possible combinations of paternal genotypes (if the minimum number of fathers is greater than one) for a set of offspring genotypes. This analysis excluded all embryos that had any mismatches to their mothers ( $\mathrm{n}=11$ out of a total of 722 embryos genotyped), because GERUD does not allow such mismatches. For each set of embryos, all possible paternal genotype combinations generated by GERUD were checked against the actual genotypes of all males included in the study ( $\mathrm{n}=69)$, and any matches were included as possible fathers of all or part of the clutch. This method yielded results similar to an analysis based on simple inclusion or exclusion of the female's social partner, but it avoided subjective bias in favor of the social partner as the father. GERUD also estimates the number of progeny from the total set of offspring genotypes attributable to a sire with each possible paternal genotype. There was no a priori expectation that all sampled embryos would be attributable to a male whose genotype was represented in the data set, as only a small subset of the overall population was included in the analysis.

At least 2 factors could result in the false exclusion of a male as the father of an embryo. Mutations may occur during gamete formation, resulting in apparent mismatches between true parents and offspring. Alternatively, genotyping errors that occur during amplification (such as mispriming) or allele scoring may result in mismatches between parents and offspring, and can result in substantial rates of false parentage exclusions (Hoffman \& Amos 2005). Most embryos did not yield enough DNA to allow replication of PCRs to check for amplification errors, although for all families showing any mismatches to the mother or the putative father, the parent was re-amplified at the mismatched locus for confirmation of the parent's genotype; in all cases the original parental genotype was confirmed. In addition, the program MICRO-CHECKER (van Oosterhaut et al. 2004) was used on the adult data set to examine the occurrence of 3 common scoring problems in microsatellite data sets: misscoring of stutter bands, large allele dropout, and null alleles.
If mothers are known, then any mismatches that occur between mothers and embryos can be attributed to either mutations or to genotyping errors. Therefore, the frequency of mother-offspring mismatches can be considered a baseline level for false parentage exclusions (although in some taxa, mutation rates at microsatellite loci are thought to differ between males and females; Ellegren 2000). The number of families with maternal, ambiguous, and paternal mismatches among the total set of families with any mismatched embryos were calculated and the number of families with maternal and paternal mismatches were compared using a $\chi^{2}$ test (with $\alpha=$ 0.05). Ambiguous mismatches may occur when an embryo carries an allele that is shared by both putative parents, but carries a second allele that is a mismatch to both parents. In such cases, the shared allele could have come from either parent, although, if one parent is known (as for snapping shrimp), as long as the mutation and scoring error rates are low relative to the rate of extra-pair parentage, the shared allele is more likely to come from the known parent. To explore the power of the data set to detect multiple paternity, estimates of the probability of detection of multiple paternity (PrDM) were obtained using Monte Carlo simulations in the program PrDM (Neff \& Pitcher 2002). This simulation considers the number of loci and allele frequencies at those loci, the number of fathers, and the relative paternal representation of each father (paternal skew), to generate estimates of PrDM for various sample sizes of genotyped embryos. PrDM estimates were generated under the assumption of 2 and 3 fathers per clutch, and paternal skews of $50: 50,75: 25$ or $90: 10$ (2 fathers), and $33: 33: 33$ or 80:10:10 (3 fathers), for sample sizes of 6, 8, or 14 embryos genotyped.

\section{RESULTS}

A total of 854 individuals (132 adults, 722 embryos) was included in the genotype data set. All 5 loci were variable, with expected heterozygosities ranging from 0.480 to 0.917 (Table 1), and only one locus, Aa36, showed significant deviation from the Hardy-Weinberg equilibrium. Estimates using CERVUS indicated total exclusionary power for the 5 loci of 0.994 , assuming one parent is known (Table 1). Tests for linkage disequilibrium performed using GenePoP indicated no significant linkage between any pairs of loci $(p>0.05$ for all pairwise comparisons after Bonferroni correction). Analysis using MICRO-CHECKER indicated no evidence for misscoring due to stutter bands, large allele dropout, or null alleles at any of the 5 loci in the adult data set. In addition, using GIMLET, analysis of 
repeated genotypes from a random subset of 20 adults indicated evidence of false alleles at only one locus, Aa36; however, this analysis indicated that all 5 loci were subject to varying rates of null alleles (Table 1).

Of the 132 adults, 118 were assigned from field data as 'paired', and among this set of 59 pairs, 52 included females that were brooding embryos. Four additional females were collected without males, and 2 of these were brooding embryos. Therefore, a total of 52 complete 'families' (mother, putative father, and a total of 694 offspring), and 2 partial families (mother and a total of 28 offspring) was included in the genotyping data set. In addition, 10 unpaired males were collected, and these were also genotyped as potential extra-pair fathers. One female was carrying only 6 embryos, and 2 females were carrying 8 embryos, and for these 3 females, all embryos were genotyped. From all other females, a total of 14 embryos were genotyped $(\bar{x}=13.4)$.

Analysis using GERUD yielded a single male parent for 37 of the 54 clutches. For all of these 37 clutches, females were collected with a social partner, and the social partner was the only male in the collection with the paternal genotype predicted by GERUD. In the 17 remaining clutches, GERUD predicted a minimum of 2 fathers, though in all cases this was based on the presence of more than 2 paternal alleles at a single locus only. Fifteen of these 17 clutches were from females that were collected with a social partner, and for all of these 15 clutches, the only match among any of the possible combinations of male parents was to the female's social partner, indicating that the social partner was a likely sire of at least part of the female's clutch. For these 15 families, the proportion of genotyped embryos that had no mismatch to the female's social partner ranged from 0.57 to $0.93(\bar{X}=0.82)$; thus, in all cases of possible multiple paternity, the female's social partner sired a majority of the clutch. A closer examination of these 15 families revealed that for 5 families, only a single embryo was not consistent with the social male partner's genotype, and in these cases, the mismatch was caused by a double homozygous condition for a maternal allele at one locus in the embryo (a possible paternal null allele). The last 2 clutches assigned to 2 sires were carried by females collected without social partners, and no male in the collection matched any of the fathers' genotypes predicted by GERUD. In summary, of 694 embryos genotyped from females collected with a social male partner, 645 were assigned to sires whose genotypes matched only the mothers' social partners, and 38 were assigned to sires whose genotypes did not match those of any males in the collection; an additional 11 embryos were excluded from the GERUD analysis because of mother-offspring mismatches, to yield an in-pair paternity rate of $94.4 \%$.
Each of the 38 offspring not assigned to any male in the collection was a mismatch to its mother's social partner at a single locus, for a total of 38 putative fatheroffspring mismatches out of 694 comparisons. However, among families with mismatches, the mismatched locus varied (Table 1); in other words, there was no sign of consistent mismatches at one or a subset of the 5 genotyped loci. In contrast, there were 11 mother-offspring mismatches out of 722 mother-offspring comparisons, and 7 ambiguous mismatches. Because female caridean shrimps adhere their embryos to their pleopods as they are spawned (Bauer 2004), mismatches between mothers and offspring are almost certainly the result of mutations or errors, rather than multiple maternity. There were more families with putative father-offspring mismatches ( $\mathrm{n}=15$ out of 52 complete families) than with mother-offspring mismatches ( $\mathrm{n}=8$ out of 54 partial and complete families), but this difference was not significant $\left(\chi^{2}=3.07, \mathrm{df}=1, \mathrm{p}>0.05\right)$.

One locus, Aa36, showed a significant heterozygote excess relative to expectations under Hardy-Weinberg equilibrium. In another investigation, this locus showed no significant deviation from the HardyWeinberg equilibrium at 6 of 7 populations, but showed a heterozygote excess at one population (Mathews 2007). This locus is the least variable of the 5 , with the 2 most common alleles differing by one repeat unit, and one possible explanation for the excess of heterozygotes would be misscoring of stutter bands, which can result in an excess of adjacent allele heterozygotes (Hoffman \& Amos 2005). Only one family showed a parent-offspring mismatch at this locus (a single offspring scored as a double heterozygote for an allele present in the mother only).

The PrDM under the sample size of 14 genotyped embryos varied depending on the inferred reproductive skew (Table 2). If 2 males fertilize approximately equal proportions of a female's clutch, the PrDM at $\mathrm{n}=14$ is high (1.00), but this decreases with increasing paternal skew. Therefore, if multiple mating results in a strong fertilization bias among males, then the frequency of multiple mating is likely to be underestimated by this data set.

Table 2. Alpheus angulosus. Probabilities of detecting multiple paternity for different numbers of offspring genotyped and under various levels of reproductive skew (\% clutches fertilized by mating males) for clutches sired by 2 or 3 males

\begin{tabular}{|lccccc|}
\hline \multirow{2}{*}{$\begin{array}{l}\text { No. offspring } \\
\text { genotyped }\end{array}$} & $50: 50$ & $75: 25$ & $90: 10$ & $33: 33: 33$ & $80: 10: 10$ \\
\cline { 2 - 6 } & 0.95 & 0.80 & 0.45 & 0.99 & 0.72 \\
8 & 0.99 & 0.89 & 0.56 & 0.99 & 0.82 \\
14 & 1.00 & 0.98 & 0.76 & 1.00 & 0.95 \\
\hline
\end{tabular}




\section{DISCUSSION}

Although snapping shrimp are widely reported as occurring in heterosexual pairs, mating and parentage interactions among individuals have been poorly understood. This study indicates that males are the genetic sires of most or all of the embryos carried by their social partners: in the GERUD analyses, reconstructed paternal genotypes matched the mothers' social partners for $94.4 \%$ of embryos. Therefore, male social partners apparently have a strong advantage over other males in fertilizing the clutches of their social partners, resulting in high rates of in-pair paternity in this species.

Temporary heterosexual pairing occurs in many crustaceans in which males engage in mate-guarding (Jormalainen 1998). For example, female American lobsters Homarus americanus share a shelter with a male for some time prior to, and following, molting and mating - a social system that has been described as 'serial monogamy' (Cowan \& Atema 1990) - and in amphipods, pre-copulatory mate-guarding by males can last for extended periods of time (Elwood \& Dick 1990). In general, mate-guarding males should abandon females as soon as it becomes profitable for them to do so, and in many cases, this should be when the female's eggs are completely fertilized. However, this study indicates that males of Alpheus angulosus do not (or do not commonly) abandon their mates after fertilization; for some families, male partners were the genetic sires of embryos that had already undergone extensive development. Therefore, males of A. angulosus are apparently constrained by some other factor or factors. One possibility is that males that abandon females may be subjected to high rates of predation once they leave the burrow; though predation risks faced by individuals of $A$. angulosus have not been investigated empirically, such pressures may be strong. However, previous experiments suggest that, at least under laboratory conditions, males are more likely to leave the burrow than females (Mathews 2002a), and under artificially female-biased conditions may abandon mated females (Mathews 2002b). In addition, Knowlton (1980) reported evidence from field investigations that males of $A$. armatus are more likely to leave a territory than females. Alternatively, by not abandoning a mated female, the male may be participating in indirect paternal care-if an unpaired female was unlikely to rear the clutch of embryos to successful hatching. Finally, the models of Wickler \& Seibt (1981) and Grafen \& Ridley (1983) predict that long-term heterosexual pairing should evolve if searching for females is especially costly for males; at some point, a male will achieve a net benefit by remaining with an already mated female through her entire reproductive period, rather than abandoning her to search for a female that is closer to sexual receptivity. For snapping shrimp, populations are dense, and searching males are likely to encounter females frequently. However, searching males also face the problem of competition from other males. As the population sex ratio is $\sim 1: 1$, any male seeking a mate is likely to have to compete with at least one other male for access to that female.

In this study, though most offspring were apparently sired by their mother's social partner, many clutches $(\mathrm{n}=17,31 \%)$ showed some signals that could indicate multiple paternity, although, in each of these clutches, only at one of the 5 loci. In 5 of the 17 clutches, only a single offspring was not attributed to the mother's social partner, and the mismatched embryo was a double homozygote for a maternal allele at one locus, suggesting that the mismatch may have been caused by a paternal null allele, a likelihood that is supported by evidence from repeated genotyping analysis using GIMLET that each of the 5 loci is subject to null alleles. Therefore, a more conservative estimate of $\mathrm{n}=12$ $(22 \%)$ clutches were potentially multiply sired. In addition, some or all of these father-offspring mismatches may be attributable to genotyping errors, which may skew interpretation of microsatellite data sets (Hoffman \& Amos 2005), particularly since in all families with father-offspring mismatches, the mismatch occurred only at a single locus. Analysis from repeated genotyping of adults indicated that 4 of the 5 loci are rarely (or never) subject to genotyping errors in the form of false alleles; however, this analysis was constrained (by limited embryonic DNA) to adults only, and therefore genotyping errors associated with embryonic DNA remain unknown. For example, embryonic DNA may be subject to a higher frequency of PCR errors. Of the 8 families with mother-offspring mismatches, only 2 of these were apparent cases of null alleles (embryos homozygous for an allele carried by the putative father); the other 6 must be attributed either to false allele scores or to mutation. For socially monogamous taxa, the chance of false paternity exclusion is dependent on, among many factors, the number of mismatches that a researcher allows between the true parent and the embryos. Genotyping errors are probably present at some frequency in all microsatellite data sets, and may lead an investigator to a false inference of paternity exclusion or multiple paternity; mismatches at more than one locus, either between the same parent-offspring pair or within the same family, provide stronger evidence for exclusion of that parent, because the likelihood of errors at multiple loci must be smaller than the likelihood of an error at a single locus. In the recent literature, researchers have used various standards to estimate the number and identity 
of fathers in similar data sets. For example, some investigators have considered the presence of mismatches or 3+ paternal alleles at a single locus as evidence for extra-pair or multiple paternity (Bilodeau et al. 2005, Cohas et al. 2006). Other investigators have more conservatively considered that mismatches or 3+ paternal alleles in at least 2 loci are required to provide convincing evidence of extra pair or multiple paternity (Seddon et al. 2005, Jensen et al. 2006, Whittingham et al. 2006), ostensibly to account for errors and mutations (which are more likely to result in a false mismatch than a false match). According to this rubric, the rate of extra-pair paternity in the snapping shrimp data set would be $0 \%$, with no social male partners excluded as fathers. In summary, this data set should be interpreted conservatively as evidence for primarily or entirely inpair paternity, particularly as there was no significant difference in the frequency of father-offspring and mother-offspring mismatches, and no strong conclusions can be made regarding the $\sim 6 \%$ of offspring that mismatched their putative fathers at a single locus. Additional analyses, including more loci and larger proportions of females' clutches, would be required to determine if EPCs occur at some frequency in this taxon.

Social monogamy has been described in a broad range of taxa, and is often hypothesized to be an evolutionary response to either the need for shared duties (such as parental care or territorial defense) or to a low polygyny threshold (sensu Emlen \& Oring 1977) because of environmental or physiological constraints (reviewed in Mathews 2002a). The correlation between social behavior, such as social monogamy, and parental or genetic interactions between individuals has important implications for the evolutionary dynamics of a population, as genetic interactions, and not social behavior, most closely influence the passage of alleles among generations. While less is known about genetic interactions, molecular genetic investigations indicate that the correlation between social and genetic monogamy varies widely from taxon to taxon, and is probably a function of the costs and benefits of various behavioral options to individuals (Petrie \& Kempenaers 1998, Griffith et al. 2002). For example, extra-pair parentage (EPP) has been widely reported in birds (Griffith et al. 2002), and may be a result of genetic advantages accrued to females (Foerster et al. 2003, Bouwman et al. 2006).

On the other hand, empirical investigations of other socially monogamous taxa have sometimes revealed a strong overlap between social and parental monogamy, which may result from constraints that limit opportunities for EPCs (Brotherton et al. 1997, Gardner et al. 2002). In snapping shrimp, it appears that a large majority of embryos are the result of in-pair matings, and therefore that, at least in terms of the overall proportions of offspring sired by females' social partners, social monogamy may correlate closely with genetic monogamy. Furthermore, if EPCs do occur, they are likely to account for only a minority of offspring produced in a population.

Acknowledgements. I thank the staff of the Tropical Marine Laboratory of Mote Marine Laboratory for field support, and L. Houle for laboratory assistance. Collections were carried out under Special Activity License \#045R-819 of the Florida Fish and Wildlife Conservation Commission.

\section{LITERATURE CITED}

Bauer RT (2004) Remarkable shrimps. University of Oklahoma Press, Norman, OK

Bilodeau AL, Felder DL, Neigel JE (2005) Multiple paternity in the thalassinidean ghost shrimp Callichirus islagrande (Crustacea: Decapoda: Callianassidae). Mar Biol 146: 381-385

Bouwman KM, Burke T, Komdeur J (2006) How female reed buntings benefit from extra-pair mating behaviour: testing hypotheses through patterns of paternity in sequential broods. Mol Ecol 15:2589-2600

Brotherton PNM, Pemberton JM, Komers PE, Malarky G (1997) Genetic and behavioural evidence of monogamy in a mammal, Kirk's dik-dik (Madoqua kirkii). Proc R Soc Lond B Biol Sci 264:675-681

Chace FA (1988) The caridean shrimps (Crustacea: Decapoda) of the Albatross Philippine expedition, 1907-1910. Part 5. Family Alpheidae. Smithson Contrib Zool 466:1-99

Cohas A, Yoccoz NG, Da Silva A, Goossens B, Allaine D (2006) Extra-pair paternity in the monogamous alpine marmot (Marmota marmota): the roles of social setting and female mate choice. Behav Ecol Sociobiol 59:597-605

Correa C, Thiel M (2003) Mating systems in caridean shrimp (Decapoda: Caridea) and their evolutionary consequences for sexual dimorphism and reproductive biology. Rev Chil Hist Nat 76:187-203

Cowan DF, Atema J (1990) Molt staggering and serial monogamy in American lobsters Homarus americanus. Anim Behav 39:1199-1206

Ellegren H (2000) Microsatellite mutations in the germline: implications for evolutionary inference. Trends Genet 16:551-558

Elwood RW, Dick JTA (1990) The amorous Gammarus: the relationship between precopula duration and sizeassortative mating in Gammarus pulex. Anim Behav 39:828-833

Emlen ST, Oring LW (1977) Ecology, sexual selection, and the evolution of mating systems. Science 197:215-223.

Foerster K, Delhey K, Johnsen A, Lifjeld JT, Kempenaers B (2003) Females increase offspring heterozygosity and fitness through extra-pair matings. Nature 425:714-717

Gardner MG, Bull CM, Cooper SJB (2002) High levels of genetic monogamy in the group-living Australian lizard Egernia stokesii. Mol Ecol 11:1787-1794

Gosselin T, Sainte-Marie B, Bernatchez L (2005) Geographic variation of multiple paternity in the American lobster, Homarus americanus. Mol Ecol 14:1517-1525

Grafen A, Ridley M (1983) A model of mate guarding. J Theor Biol 102:549-567 
Griffith SC, Owens IPF, Thuman KA (2002) Extra pair paternity in birds: a review of interspecific variation and adaptive function. Mol Ecol 11:2195-2212

Hoffman JI, Amos W (2005) Micosatellite genotyping errors: detection approaches, common sources and consequences for paternal exclusion. Mol Ecol 14:599-612

Jensen MP, Abreu-Grobois FA, Frydenberg J, Loeschcke V (2006) Microsatellites provide insight into contrasting mating patterns in arribada vs. non-arribada olive ridley sea turtle rookeries. Mol Ecol 15:2567-2575

Jones AG (2005) GERUD 2.0: a computer program for the reconstruction of parental genotypes from half-sib progeny arrays with known or unknown parents. Mol Ecol Notes 5:708-711

Jormalainen V (1998) Precopulatory mate guarding in crustaceans: male competitive strategy and intersexual conflict. Q Rev Biol 73:275-304

Knowlton N (1980) Sexual selection and dimorphism in two demes of a symbiotic, pair-bonding snapping shrimp. Evolution 34:161-173

Kokko H, Morrell LJ (2005) Mate guarding, male attractiveness, and paternity under social monogamy. Behav Ecol 16:724-731

Lee PLM, Hays GC (2004) Polyandry in a marine turtle: females make the best of a bad job. Proc Natl Acad Sci USA 101:6530-6535

Marshall TC, Slate J, Kruuk LEB, Pemberton JM (1998) Statistical confidence for likelihood-based paternity inference in natural populations. Mol Ecol 7:639-655

Mathews LM (2002a) Territorial cooperation and social monogamy: factors affecting intersexual behaviours in pair-living snapping shrimp. Anim Behav 63:767-777

Mathews LM (2002b) Tests of the mate-guarding hypothesis for social monogamy: Does population density, sex ratio, or female synchrony affect behavior of male snapping shrimp (Alpheus angulatus)? Behav Ecol Sociobiol 51: 426-432

Mathews LM (2003) Tests of the mate-guarding hypothesis for social monogamy: Male snapping shrimp prefer to associate with high-value females. Behav Ecol 14:63-67

Mathews LM (2006) Variable microsatellite markers for a snapping shrimp (Alpheus armillatus) species complex. Mol Ecol Notes 7:471-473

Mathews LM (2007) Evidence for restricted gene flow over small spatial scales in a marine snapping shrimp Alpheus angulosus. Mar Biol 152:645-655

Neff BD, Pitcher TE (2002) Assessing the statistical power of genetic analyses to detect multiple mating in fishes. J Fish Biol 61:739-750

Nelson K (1991) Scheduling of reproduction in relation to moulting and growth in malacostracan crustaceans. In:

Editorial responsibility: Howard Browman (Associate Editorin-Chief), Storebø, Norway
Wenner A, Kuris A (eds) Crustacean issues 7: Crustacean egg production. Balkema, Rotterdam, p 77-113

Petrie M, Kempenaers B (1998) Extra-pair paternity in birds: explaining variation between species and populations. Trends Ecol Evol 13:52-58

Poiani A, Wilks C (2000) Sexually transmitted diseases: a possible cost of promiscuity in birds? Auk 117:1061-1065

Rahman N, Dunham DW, Govind CK (2003) Social monogamy in the big-clawed snapping shrimp Alpheus heterochelis. Ethology 109:457-473

Raymond M, Rousset F (1995) Genepop (v1.2): population genetics software for exact tests and ecumenicism. J Hered 86:248-249

Seddon N, Amos W, Adcock G, Johnson P and 6 others (2005) Mating system, philopatry and patterns of kinship in the cooperatively breeding subdesert mesite Monias benschi. Mol Ecol 14:3573-3583

Seibt U, Wickler W (1979) The biological significance of the pair-bond in the shrimp Hymenocera picta. Z Tierpsychol 50:166-179

Subramoniam T (1993) Spermatophores and sperm transfer in marine crustaceans. Adv Mar Biol 29:129-214

Thiel M, Correa C (2004) Female rock shrimp Rhynchocinetes typus mate in rapid succession up a male dominance hierarchy. Behav Ecol Sociobiol 57:62-68

Toonen RJ (2004) Genetic evidence of multiple paternity of broods in the intertidal crab Petrolisthes cinctipes. Mar Ecol Prog Ser 270:259-263

Trivers RL (1972) Parental investment and sexual selection. In: Campbell B (ed) Sexual selection and the descent of man. Aldine, Chicago, IL, p 139-179

Urbani N, Sainte-Marie B, Sevigny JM, Zadworny D, Kuhnlein U (1998) Sperm competition and paternity assurance during the first breeding period of female snow crab (Chionoecetes opilio) (Brachyura: Majidae). Can J Fish Aquat Sci 55:1104-1113

Valière N (2002) GIMLET: a computer program for analysing genetic individual identification data. Mol Ecol Notes $2: 377-379$

van Oosterhout C, Hutchinson WF, Wills DPM, Shipley P (2004) MICRO-CHECKER: software for identifying and correcting genotyping errors in microsatellite data. Mol Ecol Notes 4: 535-538

Walker D, Porter BA, Avise JC (2002) Genetic parentage assessment in the crayfish Orconectes placidus, a highfecundity invertebrate with extended maternal brood care. Mol Ecol 11:2115-2122

Whittingham LA, Dunn PO, Stapleton MK (2006) Repeatability of extra-pair mating in tree swallows. Mol Ecol 15:841-849

Wickler W, Seibt U (1981) Monogamy in Crustacea and man. Z Tierpsychol 57:215-234

Submitted: May 14, 2007; Accepted: August 26, 2007

Proofs received from author(s): September 8, 2007 